\title{
Responsible leadership as an approach to facilitate Olympic work engagement via learning organization
}

\author{
Majd Megheirkouni \\ Michael Naylor \\ Daichi Oshimi
}

This is an Accepted Manuscript version of the following article, accepted for publication in Event Management.

Megheirkouni, M., Naylor, M. \& Oshimi, D. (2022) 'Responsible leadership as an approach to facilitate Olympic work engagement via learning organization'. Event Management. DOI: https://doi.org/10.3727/152599522X16419948390826 


\title{
Responsible Leadership as an Approach to Facilitate Olympic Work Engagement via Learning Organization
}

\author{
Majd Megheirkouni ${ }^{1}$, Michael Naylor ${ }^{2}$, and Daichi Oshimi ${ }^{3}$ \\ ${ }^{1}$ Event Management, The Accounting, Business \& Management Division, School of Business, \\ Law \& Social Sciences, Abertay University, UK \\ ${ }^{2}$ Sport Marketing, School of Sport \& Recreation, Auckland University of Technology, NZ \\ ${ }^{3}$ Tokai University, Dept. of Sport \& Leisure Management, Japan
}

\section{Author Note}

Majd Megheirkouni: https://orcid.org/0000-0001-5809-8520

Correspondence concerning this article should be addressed to Dr. Majd Megheirkouni, Lecturer in Event Management, The Accounting, Business \& Management Division, School of Business, Law \& Social Sciences, Abertay University, Bell St, Dundee DD1 1HG; Email: m.megheirkouni@abertay.ac.uk

Biographical notes: Dr. Majd Megheirkouni is Assistant Professor of Event ManagementSchool of Business, Law and Social Sciences, Division of Accounting Business and Management, Abertay University. His primary research interests are leadership practice in all settings including the non-profit sport sector and mega events.

Michael Naylor PhD, Head of Postgraduate, Senior Lecturer - Sport Marketing, School of Sport \& Recreation, Auckland University of Technology; Phone: + 6499219999 Ext 6627;

Email: michael.naylor@aut.ac.nz

Daichi Oshimi, Ph.D., TOKAI UNIVERSITY, Dept. of Sport \& Leisure Management, Japan 4-1-1 Kitakaname, Hiratsuka, Kanagawa 259-1292; Tel: +81(463)-58-1211; Fax: +81(463)-502056; E-mail: oshimidaichi@tsc.u-tokai.ac.jp

\section{ABSTRACT}


This study investigates the relationship between responsible leadership and work engagement using learning organization as a mediator. A quantitative approach was used in the present study. Data were collected from 302 participants, using evidence from the sports event industry in Japan. The results revealed responsible leadership positively affects learning organization and work engagement. The results also suggest that learning organization partially mediates the relationship between responsible leadership and work engagement. A qualitative approach is needed to more fully understand how/why responsible leadership development affects employee work engagement and the role of learning organization. Responsible leadership development has become essential for creating sustainable positive impacts in the sports event industry.

Keywords: Responsible leadership, learning organization, employee work engagement, the sports event industry 


\section{Responsible Leadership as an Approach to Facilitate Olympic Work Engagement via \\ Learning Organization}

\section{Introduction}

Responsible leadership is an emerging focus in the contemporary leadership literature (Maak \& Pless, 2006; Pless, 2007) as well as in sport event contexts specifically. It is defined as "the art and ability involved in building, cultivating and sustaining trustful relationships to different stakeholders, both inside and outside the corporation, and in coordinating responsible action to achieve a meaningful, commonly shared business vision” (Maak, 2007, p. 334). Responsible leadership is linked with several important outcomes (Doh \& Quigley, 2014; Pless \& Maak, 2011) such as legitimacy, trust stakeholder, relations, social capital, ethical culture, social entrepreneurship, performance, attitudes and cognitions, motivation, job satisfaction, effect on followers (Voegtlin et al., 2012), leader effectiveness and team effectiveness (Megheirkouni, 2019b). Given that responsible leadership is a social-relational and ethical phenomenon, occurring within social interactions, a responsible leader can influence the attitudes and behaviors of followers (Pless \& Maak, 2011). However, the process whereby responsible leaders influence subordinates behaviors or attitudes is not straightforward. According to Maak and Pless (2006), responsible leaders cultivate sustainable and trustful relationships with different stakeholders and to co-ordinate their action to achieve common objectives.

The relationship between responsible leadership and work engagement differs across various stakeholders inside and outside sports event settings. As a result, research on responsible leadership has followed two paths: one that attempts to clarify who should be included as a relevant other in networks of leader-stakeholder relationships, and another that seeks to investigate conceptually and empirically what might be described as responsible leader mindsets. 
Waldman and Galvin's (2008) differentiation of economic and stakeholder perspectives of responsible leadership suggest a spectrum of mindsets, ranging from high to low levels of regard for others. Similarly, Maak and Pless (2006) point out this spectrum represents the quality of responsibility, and thus responses to followers (stakeholder) concerns likely depend as much on contextual and institutional factors as on individual and organizational aspects.

The results of sport event research indicate that particular leadership behaviors or styles may refer to 'responsibility' when they help achieve positive outcomes. For example, transformational leadership, servant leadership, authentic leadership were perceived as effective in the sports event sector (Megheirkouni, 2017a; Megheirkouni, 2019a; Megheirkouni, 2021; Megheirkouni et al., 2018). Studies have also revealed that servant leaders are perceived as responsible leaders when they put others first (Megheirkouni, 2018b; Parris \& Peachey, 2013; Rieke et al., 2008; Wells \& Welty Peachey, 2016), while in other published research, it has been suggested that effective leaders are those who seek to build high-quality LMX relationships (Bang, 2011; Cranmer \& Myers, 2015, Hoye, 2004; Megheirkouni, 2017c; Megheirkouni, 2020). However, none of these studies has provided clarity on the notion of 'responsibility' in the sports event industry or how responsible leaders influence subordinates' attitudes and behaviors in that setting. Despite a growing body of research on leadership and its outcomes in the sports and events sector (Davies, 2015; Pernecky, 2015), to date work engagement (Allen \& Bartle, 2014), responsible leadership (Megheirkouni, 2019b), and learning organization (Xie, 2005) has received little attention.

Our study aims to test the effect of responsible leadership on work engagement, as well as the mediating role of learning organization in this relationship. Exploring the intervening effects of learning organization in this relationship has been specifically highlighted as lacking in 
sport event context (Megheirkouni, 2018a). By examining the relationship between responsible leadership and work engagement, the present study responds to calls for further research by Megheirkouni (2019b) on responsible leadership, Allen and Bartle (2014) on work engagement, and Xie (2005) on the notion of a learning organization.

There are three primary benefits of the current research. First, the present study extends the literature on learning organization by providing empirical evidence on its role in the sports events industry. Second, this study adds to the literature on work engagement by investigating the role of responsible leadership and learning organization as drivers of work engagement. Third, this study provides explanations of the influence of responsible leadership on work engagement via the mediating role of learning organization in sports events settings.

\section{Literature Review}

\section{The Sports Event Industry in Japan}

In 2016, the Japanese government approved the Action Plan for Strengthening Industrial Competitiveness (Prime Minister of Japan and His Cabinet, 2017). The development of the sports industry was one of the major pillars with an explicit aim to expand the size of this industry from US $\$ 50.5$ billion in 2015 to US $\$ 150.2$ billion in 2025 . There is no unified sports event classification in Japan. The Sasakawa Sports Foundation has classified sports events into two levels: top sport and lifelong sport events (2017). It has further divided these two levels into the international and local levels as well as multiple event and single event types. For example, the 2020 Olympic Games is classified as a "top sport event," "international level," and "multiple event" and Rugby World Cup 2019 as a "top sport event," "international level," and "single event". 
In addition to these mega sporting events, the World Masters Games 2021

(lifelong/international/multiple) will be held in Kansai. Furthermore, over 2,000 sporting events such as marathons, triathlons, and cycling (lifelong/international to local/single) are held every year. Japan has also held mega sporting events such as the 1964 Olympic Games and Soccer World Cup 2002. New events featuring "urban sport" have also gradually gained popularity. For example, the Tour de France Saitama Criterium has over 200,000 spectators every year (Saitama Criterium, 2019). Like in other sport event industries around the world, the success of Japanese events is dependent on effective leadership, so it's important to carefully dig deeper. As elsewhere, sport events in Japan are managed and implemented by a combination of paid employees and volunteers.

\section{Responsible Leadership and Learning Organization}

Broadly, responsible leadership refers to building good relationships with all relevant stakeholders inside and outside the organization. The essence of responsible leadership is based on the idea that leadership is a relational phenomenon because it involves interaction between a leader and followers (leader-member relationships) and comprises a social construction (DeRue \& Ashford, 2010; Grint, 2005). Pless, (2007) points out that responsible leadership refers to sharing responsibility by being an active citizen and promoting active citizenship in the workplace. Without building sustainable relationships with stakeholders, responsible leaders thus are more likely to fail to achieve shared objectives.

Many studies emphasize the role of leadership for the learning organization (e.g., Bass, 2000; Berson et al., 2006; Mahoney, 2000). Although the available empirical evidence for the relationship between responsible leadership and learning organization is limited, Marquardt (1997) argues that the learning organization needs leaders to demonstrate their support and 
model their commitment to learning. Not surprisingly, a learning organization needs leaders who have a sense of responsibility and provide a sense of direction. For example, Senge (1990) points out that

in a learning organization, leaders are designers, stewards and teachers. They are responsible for building organizations were people continually expand their capabilities to understand complexity, clarify vision, and improve shared mental models - that is they are responsible for learning .... Learning organizations will remain a 'good idea' . . until people take a stand for building such organizations. Taking this stand is the first leadership act, the start of inspiring (literally 'to breathe life into') the vision of the learning organization (p. 340).

The need for responsible leadership is heightened by various circumstances including business needs (Maak \& Pless, 2006), sport scandals (Megheirkouni, 2019b) and leadership failure (Pless \& Maak, 2011), all of which require learning in organizations for successful navigation. This is particularly true in dynamic contexts such as sport events. Importantly, it has been reported that the learning organization only be facilitated by those who have a sense of responsibility in the organization (Robbins \& Judge, 2017). The model tested in the current research assumes that responsible leadership precedes learning organization and thus has a causal effect on the learning organization. We, therefore, suggest that a sense of responsibility of the sport and event leader will be positively related to learning organization.

H1: Responsible leadership is positively associated with learning organization

\section{Learning Organization and Work Engagement}

The importance of the learning organization lies in widespread applicability within the ever-changing nature of modern organizational and event settings. Senge (1990) defines it as an 
organization that possesses an adaptive capacity to create alternative futures. Senge argues that there are five disciplines that a learning organization should possess: 1) team learning, which refers to the process that involves groups of people attempting to complete a task together and learning occurring through learning from mistakes and collective experience; 2) shared visions, which involves the skills of unearthing shared pictures of the future that foster commitment and involvement rather than compliance; 3) mental models, which are mental pictures or images that influence the way people understand the world and how they act or react; 4) personal mastery, which refers to the process of continually clarifying and deepening personal vision, focusing energies, developing patience, and seeing reality objectively; 5) system thinking, which is the ability to see interrelationships rather than linear cause-effect chains. Garvin (1993) defined the learning organization as "an organization skilled at creating, acquiring, and transferring knowledge, and at modifying its behavior to reflect new knowledge and insights” (p. 80).

As a social-psychological construct, work engagement refers to a positive, acceptable and psychological work-related state characterized by three dimensions: vigor, dedication, and absorption (Schaufeli et al., 2002). Vigor refers to high levels of energy and mental resilience while working. The dedication dimension refers to the degree to which people experience a sense of significance, pride, enthusiasm, and challenge from one's work; while absorption refers to the degree to which people are fully engaged in one's work in a time people have difficulties with detaching themselves from work (Schaufeli et al., 2006).

Literature across followership, organizational studies, HRD, and leadership indicates that although rewards, flexibility, sharing responsibilities, and autonomy are all motivational factors for followers, continuous learning and career development are perceived as the most important factors encouraging more effort in the workplace (e.g., Bakker \& Demerouti, 2007, 2008; Huang 
et al., 2010; Megheirkouni, 2017a, 2019b; Rhoades \& Eisenberger, 2007). Over the years, work engagement has been modeled both as a predictor and an outcome. In the present study, work engagement is conceptualized as a consequence of a learning organization. Therefore, taking part in a decision-making process, and sharing knowledge freely irrespective of hierarchical boundaries at work is an intrinsic motivational factor that predicts characteristics of work engagement (May et al., 2004; Rees et al., 2013). It is also correct that employees show interest in learning and development when they are being engaged (see, e.g., Gubman, 2004; Resick et al., 2007). Hence, we propose that:

H2: Learning organization is positively associated with work engagement.

\section{The Mediating Role of Learning Organization}

The relationship between leadership behaviors and work engagement has attracted much scholarly attention and is now well established across various settings (Breevaart et al., 2014; Caniëls et al., 2018; Caulfield \& Senger, 2017; Lee et al., 2019; Zhu et al., 2009). In fact, studies have showed that ethical leadership (Ahmad \& Gao, 2018; Chughtai et al., 2015; Demirtas, 2015), transformational leadership (Hoon Song et al., 2012; Tims et al., 2011; Yasin et al., 2013;

Zhu et al., 2009), servant leadership (Carter \& Baghurst, 2014; De Clercq et al., 2014), authentic leadership (Joo et al., 2016; Hsieh \& Wang, 2015) are all related to work engagement. Responsible leadership as an antecedent of work engagement remains unexplored.

Pless and Maak (2011) analyzed the emergent understanding of responsible leadership alongside related concepts including servant leadership, ethical leadership, transformational leadership, and authentic leadership. The authors concluded that responsible leadership is complementary suggesting that it is a likely antecedent of work engagement. However, the 
authors also reported distinctiveness, suggesting that the relationship between responsible leadership and work engagement should be studied further.

It has been noted that responsible leadership is a relational and ethical phenomenon (Freeman et al., 2005), embedded within the social interactions of affecting or affected by leadership. Responsible leaders are those who ensure that employment standards are adhered to; working conditions are human, safe, healthy and non-discriminatory; and employees (regardless of background, nationality, gender, age, etc.) are provided fair and equal employment opportunities where employees can feel comfortable and become involved in the planning of things that will affect them (Maak \& Pless, 2006). Therefore, responsible leadership may have a positive effect on subordinates' work engagement, although that effect likely occurs via learning organization.

There is a range of empirical evidence supporting the relationship between learning organization and work engagement. Subordinates feel competent within learning organization practice, leading to satisfaction and dedication to the organization (Rich et al., 2010). In the context of sport events, Govaerts, et al. (2011) reported that when organizations offer learning and development resources to subordinates, they are loyal which reflects work engagement. Likewise in a similar study, subordinates that were provided with an opportunity to learn and develop within sports events, demonstrated high-level work engagement (e.g., Glen, 2006; Rhoades \& Eisenberger, 2007). Career development and on-job training/off-job training are perceived as key factors that motivate employees and determine whether they stay or leave the organization (Chew \& Chan, 2008; Juhdi et al., 2013; Yean \& Yahya, 2013). Subordinates with continuous learning and development opportunities were observed to be highly engaged and inclined to exert more effort in the workplace and hence see themselves as more competent 
through such opportunities (Bakker \& Demerouti, 2008; Wade, 2006). On the other hand, a lack of work-based learning can decrease subordinates' commitment (Battistelli et al., 2019).

In the context of sport events, there is a paucity of research exploring learning organization and work engagement. However, one study in a Korean sport event context did find the positive relationship that has been noted elsewhere (Kyoung Park et al., 2014).

Despite a compelling conceptual rationale to do so, no research has yet explored learning organization as a mediator between responsible leadership in the context of sport events. Based on the rationale that has been presented which is buoyed by empirical evidence we propose that:

H3. Learning organization mediates the relationship between responsible leadership and work engagement.

\section{$<<$ INSERT FIGURE 1 HERE $>>$}

\section{Method}

\section{Sample and Data Collection}

The present study investigates the relationship between responsible leadership and employee work engagement, with learning organization conceptualized as a mediator. Data were collected from leaders embedded within several stakeholder groups of the 2020 Olympic Games. Questionnaires were emailed to directors, board members, senior managers, advisors, operational managers, academics, personal support managers, venues managers, technology and communications managers, and medical managers. Both sport event employees and volunteers are present across these various stakeholder working environments. An introductory letter from the authors included information about the purpose of the study, and the potential participants for the present study. Follow-up techniques (Messer \& Dillman, 2011) were used to facilitate a better survey response rate. Reminder notices were emailed four weeks later. In addition, the 
confidentiality and anonymity of the answers were guaranteed and it was emphasized that the organization would receive only aggregated results.

Of the 400 distributed surveys, 302 questionnaires were returned to the researchers (75.5\% response rate). From the 302 participants who completed the questionnaire, $44 \%$ were males and $56 \%$ were female. In terms of age, $11 \%$ were more than 51 years old, $51 \%$ were 31 50 , and $38 \%$ were less than 30 . In terms of events experience, $22 \%$ had less than 5 years of events experience, $53 \%$ had between 5 and 10 years experience, while $25 \%$ had more than 10 years of events experience.

\section{Instruments}

The Socially Responsible Leadership Scale (SRLS) was originally developed by Tyree (1998) but adapted and validated by Dugan (2006). That version features a reduced number of number of items (68) and was used in this study. The SRLS-Revised Version 2 includes several dimensions including consciousness of self, congruence, commitment, common purpose, collaboration, controversy with civility, citizenship, and change. Sample items are: "I can describe how I am similar to other people", "I support what the group is trying to accomplish", "I can identify the differences between positive and negative change". The scale was measured using a 5-point Likert scale ranging from 1 (strongly disagree) to 5 (strongly agree). The Cronbach $\alpha$ value of the scale in this research context is 0.84 .

Learning organization was measured by the Dimensions of Learning Organization Questionnaire (DLOQ) validated and revised by Watkins and Marsick, (1997, Marsick \& Watkins, 2003). While there are other instruments available in the area of organizational learning (Garvin, 2000; Templeton et al., 2002), the abbreviated 21-item DLOQ was chosen for the study because it was specifically designed as a diagnostic tool to measure changes in organizational 
learning practices and culture (Marsick \& Watkins, 2003), and it has been validated as a research tool in terms of the goodness-of-fit-index (Ellinger et al., 2002; Lien et al., 2006; Yang et al., 2004). Sample items are: “Opportunities for ongoing education and growth are provided”, "People gain productive reasoning skills to express their views and the capacity to listen and inquire into the views of others". Each item was measured using a 5-point Likert scale ranging from 1 (strongly disagree) to 5 (strongly agree). The Cronbach $\alpha$ value for this scale in this context is 0.87 .

Work engagement was measured by the nine-item, short version of the Utrecht Work Engagement Scale (UWES) developed by Schaufeli et al. (2006). The scale includes three dimensions: vigor, dedication, and absorption. Each of the nine items was measured using a 7point scale ranging from 1 (Never) to 7 (Daily). Sample items include "At my job, I feel strong and vigorous." "I find the work that I do full of meaning and purpose." and "Time flies when I am working". Cronbach's alpha internal consistency reliability of the UWES is .91 in this study.

\section{Procedure}

The authors controlled for age, gender, and work experience in the present study to rule out alternative explanations for the findings. A confirmatory factor analysis (CFA) was conducted to evaluate the model fit of the measurement model. Structural equation modeling was adopted in the present study to test the study hypotheses after confirming the model fit. Additionally, the mediating role of learning organization between responsible leadership and work engagement was tested using the Preacher and Hayes (2004) method.

$<<$ INSERT TABLE 1 HERE $>>$

\section{Results}

\section{Reliability and Validity Assessment}


A confirmatory factor analysis (CFA) was initially performed on the full measurement model that comprises the three factors and a total of 98 items. Fit indices suggested that the initial full measurement model (Model I) did not fit the data well. As suggested by Hoyle (2015), Consideration of modification indices and standard residual covariances (Hoyle, 2015), led to the deletion of nine items from the responsible leadership scale, five items from the learning organization scale, and one item from the work engagement scale and a subsequent respecification of the model (Byrne, 2001; Hair et al., 2006; Schermellech-Engel et al., 2003). The revised measurement model (Model II), comprising of three factors and 83 items improved had better fit as shown in Table $2:\left(\chi^{2}=364, d f=266 ; \chi^{2} / d f=1.57\right.$; GFI $=.93 ; \mathrm{NFI}=.95 ; \mathrm{CFI}=$ .92$, RMSEA $=.04)$.

\section{$<<$ INSERT TABLE 2 HERE $>>$}

To assess the potential for common method bias, Harman's single-factor test was conducted. The independent and dependent variables (responsible leadership, learning organization, and work engagement) loaded on a single factor $\left(\chi^{2}=2648, d f=448 ; \chi^{2} / d f=5.43\right.$; $\mathrm{GFI}=.42 ; \mathrm{NFI}=.49 ; \mathrm{CFI}=.40, \mathrm{RMSEA}=.23)$. The model fit for the data was significantly worse, which suggests 1) the common method bias would likely not account for the pattern of results reported in the present study (Hair et al., 2006), and 2) the three-factor model demonstrated a better model fit. Taken together, these results offer evidence of construct validity for the instruments employed in the present study.

\footnotetext{
$<<$ INSERT TABLE 3 HERE $>>$

$<<$ INSERT TABLE 4 HERE $>>$
}

\section{Hypothesis Testing}


Structural equation modeling (SEM) was conducted to test all hypotheses in the theoretical model. Compared to the direct effect and full mediation models, the partial mediation model had better fit to the data (Table 3). The mediating role of learning organization between responsible leadership and work engagement was tested using Preacher and Hayes's (2004) method. Hypothesis 1 proposes that responsible leadership would be related to learning organization. As shown in Table 4, the results showed that the path between responsible leadership and learning organization was significant $(\beta=.27, p<.01)$, thus Hypothesis 1 was supported. Hypothesis 2 proposes that learning organization held a significant positive relationship with work engagement. The results also revealed that this relationship was significant $(\beta=.47, p<.001)$, thus Hypothesis 2 was supported. Hypothesis 3 proposes that learning organization would mediate the relationship between responsible leadership and work engagement. The results revealed that this hypothesis received partial support, given that the effect of responsible leadership on work engagement was reduced $(\beta=.19, p<.01)$, but remained significant $(\beta=.12, p<.01)$.

\section{Discussion}

The aim of this study was to explore the relationship between responsible leadership and work engagement using learning organization as a mediator. These relationships were tested for the first time among sport event professionals. Those surveyed were leaders in a dynamic and high profile context - the Olympic Games - ideal for exploring these constructs of increasing interest in sport and event research.

The most important findings of the study are that: a) responsible leadership positively affects learning organization and work engagement, b) learning organization partially mediates relationship between responsible leadership and work engagement. These findings contribute to 
the field and ongoing assessment of contemporary leadership approaches with a focus on responsible leadership, and its relationship to positive organizational outcomes. In his review of sport leadership research, Megheirkouni (2018a) pointed out the need for consideration and exploration of leadership theories and approaches in all sport settings, including events. To our knowledge, this study is not only the first to investigate responsible leadership in a sport event settings, but also to generate results confirming the importance of responsible leadership to positive organizational outcomes such as work engagement. The principle theoretical contribution therefore is that this study provides insight into the processes through which leadership influences outcome variables, a neglected area of leadership research in sport management (Megheirkouni, 2018a, 2019d).

In the complex and fast moving environment of sport mega events, it is imperative for those involved in event planning and delivery to adopt responsible leadership behaviors and a supportive learning culture to improve employee engagement. A learning culture particularly is a necessity in complex and competitive environments (Pemberton et al., 2001). It is becoming more important than ever for leaders in and around sport mega events to demonstrate social responsibility, foster a learning culture and enhance work engagement before and during the event (See, e.g., Werner et al., 2015).

Educational and learning opportunities have been identified as major factors underpinning volunteer motivation at Olympic Games (Farrell et al., 1998). To this end, the Tokyo 2020 organising committee have priorised the establishment of a learning culture by planning group training and e-learning for volunteers (International Olympic Committee, 2019). The results of this study are consistent with both the results of related research and the priorities of those staging mega sport events. The results of the present study suggests that further attention 
should focus on developing responsible leadership behaviors that would support learning organization, and enhance work engagement. In fact the results here broaden our understanding of this notable trend by suggesting that in a sport event context, learning organizations can be specifically initiated by responsible leadership and result in heightened employee work engagement.

The significant relationship uncovered here between responsible leadership and learning organization supports $\mathrm{H} 1$. This finding aligns with previous work recognizing social responsibility as a style of leadership that can interrelate with learning organization. For example, Zadek's (2004) five stages of the organizational experience: (strategic, managerial, compliance, defensive, and civil), incorporate social responsibility but also capture stages of organizational learning and form a useful framework for mega sport events as well. When a leader acts responsibly, including as a steward, citizen, visionary, servant, coach, architect, storyteller, meaning enabler, and change agent, it can have positive implications for inside and outside the organization (Maak \& Pless, 2006). Responsible leaders of sport organizations who demonstrate these roles are likely to facilitate a learning organization. It is not that the learning organization in the sport event sector fails to materialize in conjunction with other leadership approaches which often overlap (Pless \& Maak, 2011), but rather we argue that there is an intuitive path starting with responsible leadership particularly.

It also emerged in this study that there is a significant relationship between learning organization and work engagement which supports $\mathrm{H} 2$. This result is consistent with extant research on this relationship (Kyoung et al., 2014; Malik \& Garg, 2020) and, importantly, provides evidence that this phenomenon pervades sport event contexts as well. It is noteworthy 
that Facilitating learning organizations in the sports event sector is therefore critical, as a lack of engagement from employees in the event industry can be catastrophic.

The current study answers the call from Pless and Maak (2011) to carry out research with the aim of better understanding the complexity of responsible leadership. Specifically, this research sought to explore a potential intervening role of a third construct (i.e., learning organization) on an important relationship (responsible leadership and work engagement). The evidence in support of partial mediation (and H3) found here is revealing of some of the complexity around responsible leadership that has been suggested. We argue that leaders in and around sport mega events should demonstrate responsibility not only because it will ultimately foster work engagement directly, but also continuously encourage development within a learning organization, which will in turn also enhance work engagement.

\section{Implications for Practice}

In the present study, evidence emerged revealing the importance of responsible leadership and learning organization on sport event employee and volunteer work engagement. These variables have not yet been simultaneously explored in a mega sport event context, so implications for practice are abundant. Most importantly, responsible leadership is a very sensible starting point for those in mega sport event leadership roles. There is obvious intuitive appeal given how well the stakeholder focus of this approach aligns with the nature of mega events which are the ultimate confluence of stakeholders working together. However, learning organizations and engaged workers are equally important in the context of a fast moving, dynamic environment which charactertises mega event delivery. The fact that both responsible leadership and learning organization are related to work engagement means that both must be a priority to mega event leaders. 
Digging deeper, the results of this study suggest that leaders in the sports event sector should emphasize the moral-legal standard, internal obligation, concern for others, concern consequences, and self-judgment which are all responsible leadership behaviors to enhance the engagement of both employees and volunteers. This can occur by facilitating well-designed learning and development programs, workshops, seminars, and collective and short-term educational courses on responsible leadership (Maak \& Pless, 2006) in the context of sport mega events that cope with a complex network of stakeholders (Leopkey \& Parent, 2009). These initiatives should result in sport event employees and volunteers being more committed to their role and being more effective in it.

The resource required to enhance human capital, skills and competencies to achieve competitive advantage in the sports event sector can be daunting (Megheirkouni, 2018b, Megheirkouni, 2019d). However, it is more important than ever and a 'permanent' learning organization environment ought to be the aim to sustain effectiveness in competitive sport mega events. Learning occurs at the individual, group, and organization levels, each informing the others. These three levels of learning are linked by four social and psychological processes: intuiting, interpreting, integrating, and institutionalizing. Within these processes, cognition affects behavior, and vice versa (Vera \& Crossan, 2004). To do this, leaders in the sports event industry need to understand followers needs if they want to become a learning organization. This can enhance work engagement. A truly responsible leader is one who encourages learning but also promotes a wider culture of learning in sport events environments. Therefore, leaders must be hired into key mega event roles who are capable of espousing that culture.

\section{Limitations}


Although the present study broadens our understanding of responsible leadership, it has several limitations. Demographics and other personal characteristics are important considerations when it comes to leader effectiveness but were not taken into consideration in the current study. Future researchers in this area may also wish to consider leadership through alternate lenses (servant leadership for e.g.,) to explore how they may relate to learning organization in sport event contexts. The generalizability of the findings (or lack thereof) should also be acknowledged here and this can of course be assessed through the benefits of future research. . Generalizability of the findings to non-sport events, sectors, or countries may be limited.

An additional important next step for future research is to validate the findings of the present study to determine the extent to which the findings of the present study extend to other sports event settings in Japan, although of course one cannot be sure that the findings of the present study extend to all sports event settings such as, non-mega sport events. It is possible that the overall level of effects of responsible leadership might be stronger in cultures where the nonprofit sector is controlled by governments, such as in the Middle East and North Africa (MENA). For example, chief executives, presidents, or chairmen of the sports event industry who are politically supported tend to place this support as a strategy for building and sustaining good relationships with all relevant stakeholders (Megheirkouni, 2017b).

\section{Conclusion}

The present study makes a significant contribution to the literature on leadership in sport and event industry in that it has integrated for the first time a responsible leadership approach into a model applicable to the context of sport mega events. More specifically, we have investigated the relationship between responsible leadership and work engagement using learning organization as a mediator. The results show that responsible leadership positively 
affects learning organization and work engagement. In addition, learning organization partially mediates the relationship between responsible leadership and work engagement. 


\section{REFERENCES}

Ahmad, I., \& Gao, Y., (2018). Ethical leadership and work engagement: The roles of psychological empowerment and power distance orientation. Management Decision, 56(9), 1991-2005. https://doi.org/10.1108/MD-02-2017-0107

Allen, J. B., \& Bartle, M. (2014). Sport event volunteers' engagement: Management matters. Managing Leisure, 19(1), 36-50. https://doi.org/10.1080/13606719.2013.849502

Bakker, A. B., \& Demerouti, E. (2007). The job demands-resources model: State of the art, Journal of Managerial Psychology, 22(3), 309-328. https://doi.org/10.1108/02683940710733115

Bakker, A. B., \& Demerouti, E. (2008). Towards a model of work engagement. Career Development International, 13(3), 209-223. https://doi.org/10.1108/13620430810870476

Bang, H. (2011). Leader-member exchange in nonprofit sport organizations: The impact on job satisfaction and intention to stay from the perspectives of volunteer leaders and followers. Nonprofit Management and Leadership, 22(1), 85-105.

https://doi.org/10.1002/nml.20042

Bass, B. M. (2000). The future of leadership in learning organizations. Journal of Leadership \& Organizational Studies, 7(3), 18-40. https://doi.org/10.1177/107179190000700302

Battistelli, A., Odoardi, C., Vandenberghe, C., Di Napoli, G., \& Piccione, L. (2019). Information sharing and innovative work behavior: The role of work-based learning, challenging tasks, and organizational commitment. Human Resource Development Quarterly. 30(3), 361-381. https://doi.org/10.1002/hrdq.21344 
Berson, Y., Nemanich, L. A., Waldman, D. A., Galvin, B. M., \& Keller, R. T. (2006).

Leadership and organizational learning: A multiple levels perspective. The Leadership Quarterly, 17(6), 577-594. https://doi.org/10.1016/j.leaqua.2006.10.003

Breevaart, K., Bakker, A. B., Hetland, J., Demerouti, E., Olsen, O. K., \& Espevik, R. (2014). Daily transactional and transformational leadership and daily employee engagement. Journal of Occupational and Organizational Psychology, 87(1), 138-157. https://doi.org/10.1111/joop.12041

Byrne, B. M. (2001). Structural equation modeling with AMOS, EQS, and LISREL: Comparative approaches to testing for the factorial validity of a measuring instrument. International Journal of Testing, 1(1), 55-86. https://doi.org/10.1207/s15327574ijt0101_4

Caniëls, M. C. J., Semeijn, J. H., \& Renders, I. H. M. (2018). Mind the mindset! The interaction of proactive personality, transformational leadership and growth mindset for engagement at work. Career Development International, 23(1), 48-66. https://doi.org/10.1108/CDI$\underline{11-2016-0194}$

Carter, D., \& Baghurst, T. (2014). The influence of servant leadership on restaurant employee engagement. Journal of Business Ethics, 124(3), 453-464. https://www.jstor.org/stable/24033282

Caulfield, J. L., \& Senger, A. (2017). Perception is reality: Change leadership and work engagement. Leadership \& Organization Development Journal, 38(7), 927-945. https://doi.org/10.1108/LODJ-07-2016-0166 
Chew, J., \& Chan, C. C. A. (2008). Human resource practices, organizational commitment and intention to stay. International Journal of Manpower, 29(6), 503-522. https://doi.org/10.1108/01437720810904194

Chughtai, A., Byrne, M. \& Flood, B. (2015). Linking ethical leadership to employee well-being: The role of trust in supervisor. Journal of Business Ethics, 128(3), 653-663. https://doi.org/10.1007/s10551-014-2126-7

Cranmer, G. A., \& Myers, S. A. (2015). Sports teams as organizations: A leader-member exchange perspective of player communication with coaches and teammates. Communication \& Sport, 3(1), 100-118.

Davies, A. (2015). Life after a festival: Local leadership and the lasting legacy of festivals. Event Management, 19(4), 433-444. https://doi.org/10.3727/152599515X14465748512524

De Clercq, D., Bouckenooghe, D., Raja, U., \& Matsyborska, G. (2014). Servant leadership and work engagement: The contingency effects of leader-follower social capital. Human Resource Development Quarterly, 25(2), 183-212. https://doi.org/10.1002/hrdq.21185

Demirtas, O. (2015). Ethical leadership influence at organizations: Evidence from the field. Journal of Business Ethics, 126(2), 273-284. https://doi.org/10.1007/s10551-013-1950-5

DeRue, D. S., \& Ashford, S. J. (2010). Who will lead and who will follow? A social process of leadership identity construction in organizations. Academy of Management Review, 35(4), 627-647. https://doi.org/10.5465/amr.35.4.zok627

Doh, J. P., \& Quigley, N. R. (2014). Responsible leadership and stakeholder management: Influence pathways and organizational outcomes. Academy of Management Perspectives, 28(3), 255-274. https://doi.org/10.5465/amp.2014.0013 
Dugan, J. P. (2006). Involvement and leadership: A descriptive analysis of socially responsible leadership. Journal of College Student Development, 47(3), 335-343. https://doi.org/10.1353/csd.2006.0028

Ellinger, A. D., Ellinger, A. E., Yang, B., \& Howton, S. W. (2002). The relationship between the learning organization concept and firms' financial performance: An empirical assessment. Human Resource Development Quarterly, 13(1), 5-22. https://doi.org/10.1002/hrdq.1010

Farrell, J. M., Johnston, M. E., \& Twynam, G. D. (1998). Volunteer motivation, satisfaction, and management at an elite sporting competition. Journal of Sport Management, 12(4), 288300. https://doi.org/10.1123/jsm.12.4.288

Freeman, R. E., Martin, K., Parmar, B., Cording, M. P., \& Werhane, P. H. (2005). Leading through values and ethical principles. In R. Burke, \& C. Cooper (Eds.), Inspiring leaders (pp. 149-174). Routledge.

Garvin, D. A. (1993, July-August). Building a learning organization. Harvard Business Review, 71(4), 78-91.

Garvin, D. A. (2000), Learning in Action: A Guide to Putting the Learning Organization to Work. Harvard Business School Press.

Glen, C. (2006). Key skills retention and motivation: The war for talent still rages and retention is the high ground. Industrial and Commercial Training, 38(1), 37-45. https://doi.org/10.1108/00197850610646034

Govaerts, N., Kyndt, E., Dochy, F., \& Baert, H. (2011). Influence of learning and working climate on the retention of talented employees, Journal of Workplace Learning, 23(1), 35-55. https://doi.org/10.1108/13665621111097245 
Grint, K. (2005). Problems, problems, problems: The social construction of 'leadership'. Human relations, 58(11), 1467-1494. https://doi.org/10.1177/0018726705061314

Gubman, E. (2004). From Engagement to Passion for Work: The Search for the Missing Person. Human Resource Planning, 27(3), 25-26.

Hair, J. F., Black, W. C., Babin, B. J., Anderson, R. E., \& Tatham, R. L. (2006). Multivariate Data Analysis $\left(6^{\text {th }}\right.$ Ed). Pearson University.

Hoon Song, J., Kolb, J. A., Hee Lee, U., \& Kyoung Kim, H. (2012). Role of transformational leadership in effective organizational knowledge creation practices: Mediating effects of employees’ work engagement. Human Resource Development Quarterly, 23(1), 65-101. https://doi.org/10.1002/hrdq.21120

Hoye, R. (2004). Leader-member exchanges and board performance of voluntary sport organizations. Nonprofit Management and Leadership, 15(1), 55-70. https://doi.org/10.1002/nml.53

Hoyle, R. H. (2015). Handbook of structural equation modeling. Guilford press.

International Olympic Committee. (2019, 25 January). More than 200,000 applications received for Tokyo 2020 Volunteer Programme. https://www.olympic.org/news/more-than-200000-applications-received-for-tokyo-2020-volunteer-programme

Hsieh, C-C., \& Wang, D-S. (2015). Does supervisor-perceived authentic leadership influence employee work engagement through employee-perceived authentic leadership and employee trust?. The International Journal of Human Resource Management, 26(18), 2329-2348. https://doi.org/10.1080/09585192.2015.1025234 
Huang, J-Y., Chou, T-C., \& Lee, G-G. (2010). Imitative innovation strategies: Understanding resource management of competent followers. Management Decision, 48(6), 952-975. https://doi.org/10.1108/00251741011053488

Joo, B-K., Lim, D. H., \& Kim, S. (2016). Enhancing work engagement: The roles of psychological capital, authentic leadership, and work empowerment. Leadership \& Organization Development Journal, 37(8), 1117-1134. https://doi.org/10.1108/LODJ-01$\underline{2015-0005}$

Juhdi, N., Pa'wan, F., \& Hansaram, R. M. K. (2013). HR Practices and Turnover intention: The mediating roles of organizational commitment and organizational engagement in a selected region in Malaysia. The International Journal of Human Resource Management, 24(15), 3002-3019. https://doi.org/10.1080/09585192.2013.763841

Kyoung Park, Y., Hoon Song, J., Won Yoon, S., \& Kim, J. (2014). Learning organization and innovative behavior: The mediating effect of work engagement. European Journal of Training and Development, 38(1/2), 75-94. https://doi.org/10.1108/EJTD-04-2013-0040

Leopkey, B., \& Parent, M. M. (2009). Risk management issues in large-scale sporting events: A stakeholder perspective. European Sport Management Quarterly, 9(2), 187-208. https://doi.org/10.1080/16184740802571443

Lee, M. C. C., Idris, M. A., \& Tuckey, M. (2019). Supervisory coaching and performance feedback as mediators of the relationships between leadership styles, work engagement, and turnover intention. Human Resource Development International, 22(3), 257-282. https://doi.org/10.1080/13678868.2018.1530170 
Lien, B-Y., Hung, R. Y-Y., Yang, B., \& Li, M. (2006). Is the learning organization a valid concept in the Taiwanese context? International Journal of Manpower, 27(2), 189-203. https://doi.org/10.1108/01437720610666209

Maak, T. (2007). Responsible leadership, stakeholder engagement, and the emergence of social capital. Journal of Business Ethics, 74, 329-343. https://doi.org/10.1007/s10551-007$\underline{9510-5}$

Maak, T., \& Pless, N. M. (2006). Responsible leadership in a stakeholder society—A relational perspective. Journal of Business Ethics, 66(1), 99-115. https://doi.org/10.1007/s10551$006-9047-z$

Mahoney, R. (2000). Leadership and learning organizations. The Learning Organization, 7(5), 241-244. https://doi.org/10.1108/09696470010378325

Malik, P., \& Garg, P. (2020). Learning organization and work engagement: The mediating role of employee resilience. The International Journal of Human Resource Management, 31(8), 1071-1094. https://doi.org/10.1080/09585192.2017.1396549

Marquardt, M. (1997). 16 steps to becoming a learning organization (Vol. 9602). American Society for Training and Development.

Marsick, V., \& Watkins, K. (2003). Demonstrating the value of an organization's learning culture: The dimensions of the learning organization questionnaire. Advances in Developing Human Resources, 5(2), 132-151. https://doi.org/10.1177/1523422303005002002

May, D. R., Gilson, R. L. \& Harter, L. M. (2004). The psychological conditions of meaningfulness, safety and availability and the engagement of the human spirit at work. 
Journal of Occupational and Organizational Psychology, 77(1), 11-37.

https://doi.org/10.1348/096317904322915892

Megheirkouni, M. (2017a). Leadership styles and organizational learning in UK for-profit and non-profit sports organizations. International Journal of Organizational Analysis, 25(4), 596-612. https://doi.org/10.1108/IJOA-07-2016-1042

Megheirkouni, M. (2017b). Leadership competencies: Qualitative insight into non-profit sports organizations. International Journal of Public Leadership, 13(3), 166-181. https://doi.org/10.1108/IJPL-11-2016-0047

Megheirkouni, M. (2017c). Revisiting leader-member exchange theory: Insights into sport stadia management. International Journal of Event and Festival Management. 8(3), 244-260. https://doi.org/10.1108/IJEFM-03-2017-0022

Megheirkouni, M., Amaugo, A., \& Jallo, S. (2018). Transformational and transactional leadership and skills approach: Insights on stadium management. International Journal of Public Leadership, 14(4), 245-259. https://doi.org/10.1108/IJPL-06-2018-0029

Megheirkouni, M. (2018a). Mixed methods in sport leadership research: A review of sport management practices. Sports Management International Journal Choregia, 14(1), 1-20. https://doi.org/10.4127/ch.2018.0126

Megheirkouni, M. (2018b). Insights on practising of servant leadership in the events sector. Sport, Business, Management: An International Journal, 8(2), pp. 134-152. https://doi.org/10.1108/SBM-01-2017-0001

Megheirkouni, M. (2019a). Leadership and Decision-Making Styles in Large-Scale Sporting Events. Event Management, 22(5), pp. 785-801(17) DOI: https://doi.org/10.3727/152599518X15299559876162 
Megheirkouni, M. (2019b). Responsible leadership as a mediator between emotional intelligence and team outcomes in sport organizations. International Journal of Sport Management, 20(1), 87-107. ISBN 978-0-89641-585-0.

Megheirkouni, M. (2019d). The types of authority and problems at Olympic events: insights into Grint's model of decision-making positions. Event Management, 23(6), 801-816. https://doi.org/10.3727/152599519X15506259856408

Megheirkouni, M. (2020). Psychological contract, leadership, and job satisfaction: An empirical investigation into the non-profit sports sector. Annals of Leisure Research, pp. 1-24.. https://doi.org/10.1080/11745398.2020.1769488

Megheirkouni, M (2021). Authentic leadership, empowerment and positive outcomes: Hearing the voice of the events industry. Event Management, 25(5), 445-458. https://doi.org/10.3727/152599519X15506259856615

Messer, B. L., \& Dillman, D. A. (2011). Surveying the general public over the internet using address-based sampling and mail contact procedures. Public Opinion Quarterly, 75(3), 429-457. https://doi.org/10.1093/poq/nfr021

Parris, D. L., \& Peachey, J. W. (2013). Encouraging servant leadership: A qualitative study of how a cause-related sporting event inspires participants to serve. Leadership, 9(4), 486512. $\underline{\text { https://doi.org/10.1177/1742715012470675 }}$

Pernecky, T. (2015). Sustainable leadership in event management. Event Management, 19(1), 109-121. https://doi.org/10.3727/152599515X14229071393188

Pemberton, J. D., Stonehouse, G. H., \& Yarrow, D. J. (2001). Benchmarking and the role of organizational learning in developing competitive advantage. Knowledge and Process Management, 8(2), 123-135. https://doi.org/10.1002/kpm.110 
Pless, N. M. (2007). Understanding responsible leadership: Role identity and motivational drivers. Journal of Business Ethics, 74(4), 437-456. https://doi.org/10.1007/s10551-0079518-X

Pless, N. M., \& Maak, T. (2011). Responsible leadership: Pathways to the future. Journal of Business Ethics, 98, 3-13. https://doi.org/10.1007/s10551-011-1114-4

Preacher, K. J., \& Hayes, A. F. (2004). SPSS and SAS procedures for estimating indirect effects in simple mediation models. Behavior Research Methods, Instruments, \& Computers, 36(4), 717-731. https://doi.org/10.3758/BF03206553

Prime Minister of Japan and His Cabinet. (2017). Council on Investments for the Future. https://japan.kantei.go.jp/97_abe/actions/201701/27article1.html

Rich, B. L., Lepine, J. A., \& Crawford, E. R. (2010), Job engagement: Antecedents and effects on job performance. Academy of Management Journal, 53(3), 617-635. https://doi.org/10.5465/amj.2010.51468988

Rees, C., Alfes, K., \& Gatenby, M. (2013). Employee voice and engagement: Connections and consequences, The International Journal of Human Resource Management, 24(14), 2780-2798. https://doi.org/10.1080/09585192.2013.763843

Resick, C. J., Baltes, B. B., \& Shantz, C. W. (2007). Person-organization fit and work-related attitudes and decisions: Examining interactive effects with job fit and conscientiousness. Journal of Applied Psychology, 92(5), 1446-1455. https://doi.org/10.1037/0021$\underline{9010.92 .5 .1446}$

Rhoades, L. \& Eisenberger, R. (2007). Perceived organizational support: A review of the literature, Journal of Applied Psychology, 87(4), 698-714. https://doi.org/10.1037/0021$\underline{9010.87 .4 .698}$ 
Rieke, M., Hammermeister, J., \& Chase, M. (2008). Servant leadership in sport: A new paradigm for effective coach behavior. International Journal of Sports Science \& Coaching, 3(2), 227-239. https://doi.org/10.1260/174795408785100635

Robbins, S., \& Judge, T. (2017), Essentials of Organizational Behavior (13 ${ }^{\text {th }}$ Ed.). London: Pearson.

Saitama Criteriumu. (2019). Tour de France Saitama Criterium. https://www.saitamacriterium.com/en/the-race/about

Sasakawa Sports Foundation (2017). Sport white paper. Sasakawa Sports Foundation, Tokyo, Japan. ISBN 978-4-915944-66-6

Schaufeli, W. B., Bakker, A. B., \& Salanova, M. (2006). The measurement of work engagement with a short questionnaire: A cross-national study. Educational and Psychological Measurement, 66(4), 701-716. https://doi.org/10.1177/0013164405282471

Schaufeli, W. B., Salanova, M., González-Romá, V., \& Bakker, A. B. (2002). The measurement of engagement and burnout: A two sample confirmatory factor analytic approach. Journal of Happiness Studies, 3(1), 71-92. https://doi.org/10.1023/A:1015630930326

Schermelleh-Engel, K., Moosbrugger, H., \& Müller, H. (2003). Evaluating the fit of structural equation models: Tests of significance and descriptive goodness-of-fit measures. Methods of Psychological Research Online, 8(2), 23-74.

Senge, P. M. (1990). The fifth discipline: The art and practice of the learning organization. Random House.

Templeton, G. F., Lewis, B. R., \& Snyder, C. A. (2002). Development of a measure for the organizational learning construct. Journal of Management Information Systems, 19(2), 175-218. https://doi.org/10.1080/07421222.2002.11045727 
Tims, M., Bakker, A. B., \& Xanthopoulou, D. (2011). Do transformational leaders enhance their followers' daily work engagement?. The Leadership Quarterly, 22(1), 121-131. https://doi.org/10.1016/j.leaqua.2010.12.011

Tyree, T. M. (1998). Designing an instrument to measure socially responsible leadership using the Social Change Model of leadership development. (Doctoral dissertation). University of Maryland, College Park, Maryland. (AAT 9836493)

Vera, D., \& Crossan, M. (2004). Strategic leadership and organizational learning. Academy of Management Review, 29(2), 222-240. https://doi.org/10.5465/amr.2004.12736080

Voegtlin, C., Patzer, M., \& Scherer, A. G. (2012). Responsible leadership in global business: A new approach to leadership and its multi-level outcomes. Journal of Business Ethics, 105(1), 1-16. https://doi.org/10.1007/s10551-011-0952-4

Wade, M. (2006). Developing Leaders for Sustainable Business. In T. Maak, \& N. M. Pless (Eds.), Responsible Leadership (pp. 227-244). Routledge.

Waldman, D. A., \& Galvin, B. M. (2008). Alternative perspectives of responsible leadership. Organizational Dynamics, 37(4), 327-341. https://doi.org/10.1016/j.orgdyn.2008.07.001

Marsick, V. J., \& Watkins, K. E. (2003). Demonstrating the value of an organization's learning culture: the dimensions of the learning organization questionnaire. Advances in developing human resources, 5(2), 132-151. https://doi.org/10.1177/1523422303005002002

Wells, J., \& Welty Peachey, J. (2016). Called to serve: Exploring servant leadership in the context of sport-for-development. Journal of Sport for Development, 4(7), 12-24. 
Werner, K., Dickson, G., \& Hyde, K. F. (2015). Learning and knowledge transfer processes in a mega-events context: The case of the 2011 Rugby World Cup. Tourism Management, 48, 174-187. https://doi.org/10.1016/j.tourman.2014.11.003

Xie, D. (2005). Exploring organizational learning culture, job satisfaction, motivation to learn, organizational commitment, and internal service quality in a sport organization, (Doctoral dissertation), The Ohio State University. ISBN: 0-542-21000-2.

Yang, B., Watkins, K. E., \& Marsick, V. J. (2004). The construct of the learning organization: Dimensions, measurement, and validation. Human Resource Development Quarterly, 15(1), 31-55. https://doi.org/10.1002/hrdq.1086

Yasin Ghadi, M., Fernando, M., \& Caputi, P. (2013). Transformational leadership and work engagement: The mediating effect of meaning in work. Leadership \& Organization Development Journal, 34(6), 532-550. https://doi.org/10.1108/LODJ-10-2011-0110

Yean, T. F., \& Yahya, K. K. (2013). The influence of human resource management practices and career strategy on career satisfaction of insurance agents. International Journal of Business and Society, 14(2), 193-206. http://www.ijbs.unimas.my/repository/pdf/Vol14No2paper2.pdf

Zadek, S. (2004, December). The path to corporate responsibility. Harvard Business Review, 82(12), 125-150. https://pubmed.ncbi.nlm.nih.gov/15605571/

Zhu, W., Avolio, B. J., \& Walumbwa, F. O. (2009). Moderating role of follower characteristics with transformational leadership and follower work engagement. Group and Organization Management, 34(5), 590-619. https://doi.org/10.1177/1059601108331242 


\section{Table 1}

Descriptive Statistics and Correlations Among Study Variables

\begin{tabular}{lccccccc}
\hline Variables & $M$ & $S D$ & 1 & 2 & 3 & 4 & 5 \\
\hline Age & 34.62 & 9.54 & & & & & \\
Gender & 1.24 & 0.41 & 0.07 & & & & \\
Experience & 9.65 & 4.87 & $0.21^{*}$ & 0.09 & & & \\
Responsible leadership & 3.87 & 0.64 & 0.14 & 0.10 & $0.18^{*}$ & & \\
Learning organization & 3.48 & 0.80 & $0.13^{*}$ & $0.14^{*}$ & $0.15^{*}$ & $0.41^{*}$ & \\
Work engagement & 3.24 & 0.78 & $0.27^{*}$ & $0.18^{*}$ & $0.20^{*}$ & $0.38^{*}$ & $0.52^{*}$ \\
\hline${ }^{*} p<.01$ & & & & & & &
\end{tabular}


Table 2

Goodness-of-Fit Statistics for Models

\begin{tabular}{lcccccc}
\hline Models & $\chi^{2} / d f$ & $\chi^{2} / d f$ & GFI & CFI & NFI & RMSEA \\
\hline Model I 3 factors $^{\mathrm{a}}$ & $531^{* * *}(192)$ & 2.79 & 0.71 & 0.86 & 0.81 & 0.06 \\
Model II 3 factors $^{\mathrm{b}}$ & $364^{* * *}(266)$ & 1.57 & 0.93 & 0.92 & 0.95 & 0.04 \\
Harman's one factor model $^{\mathrm{c}}$ & $2648(448)$ & 5.43 & 0.42 & 0.40 & 0.49 & 0.23 \\
\hline
\end{tabular}

Note: $\chi^{2}$,chi-square discrepancy; $d f$, degrees of freedom; GFI, goodness-of-fit index; CFI, comparative fit index; NFI, normed fit index; RMSEA, root mean square error of approximation.

${ }^{* * *} p<.001$

${ }^{a}$ Overall model fit three factors (98 items).

${ }^{\mathrm{b}}$ Overall model fit three factors ( 83 items).

' Harman's single factor model. 
Table 3

Goodness-of-Fit Statistics for Structural Equation Model Comparisons

\begin{tabular}{lccccccc}
\hline \multicolumn{1}{c}{ Models } & $\chi^{2} / d f$ & $\chi^{2} / d f$ & SRMR & GFI & NFI & CFI & RMSEA \\
\hline Direct effect model & $362^{* * *}(238)$ & 1.65 & 0.05 & 0.88 & 0.96 & 0.89 & 0.04 \\
Full mediation model & $589^{* * *}(212)$ & 2.85 & 0.06 & 0.71 & 0.80 & 0.73 & 0.06 \\
Partial mediation model & $364^{* * *}(266)$ & 1.57 & 0.04 & 0.93 & 0.92 & 0.95 & 0.04 \\
\hline
\end{tabular}

Note: $\chi^{2}$,chi-square discrepancy; $d f$, degrees of freedom; SRMR, standardized root mean square residual; GFI, goodness-of-fit index; CFI, comparative fit index; NFI, normed fit index; RMSEA, root mean square error of approximation ${ }^{* * *} p<.001$ 
Table 4

Indirect Effect of Responsible Leadership on Work Engagement via Learning Organizations

\begin{tabular}{lccc}
\hline & Learning Organization & work engagement & Indirect effect \\
\cline { 2 - 4 } & $\beta^{\mathrm{a}}$ & $\beta^{c}$ & $\beta^{c-c^{\prime}}$ \\
\hline Responsible leadership & $0.27^{* *}$ & $0.19^{* *}$ & $0.12^{* *}$ \\
Learning organization $^{\mathrm{b}}$ & - & $0.47^{* *}$ & - \\
\hline
\end{tabular}

Notes: ${ }^{* *} p<.01$

${ }^{a}$ Effect of responsible leadership on learning organization

${ }^{b}$ Effect of learning organization on work engagement

${ }^{c}$ Effect of learning organization on work engagement

c-c'Standardized indirect effect 


\section{Figure 1}

\section{Theoretical Model}

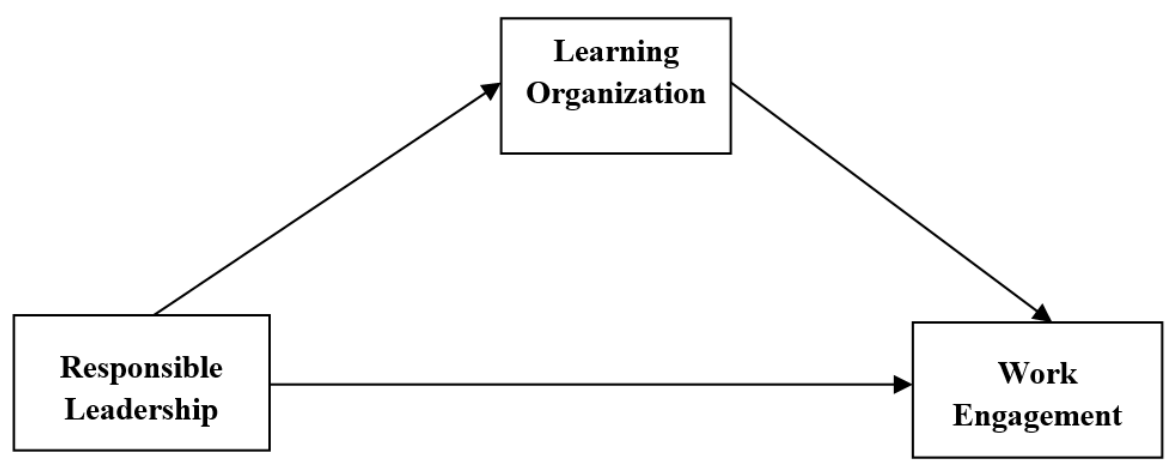

